Provided for non-commercial research and education use. Not for reproduction, distribution or commercial use.

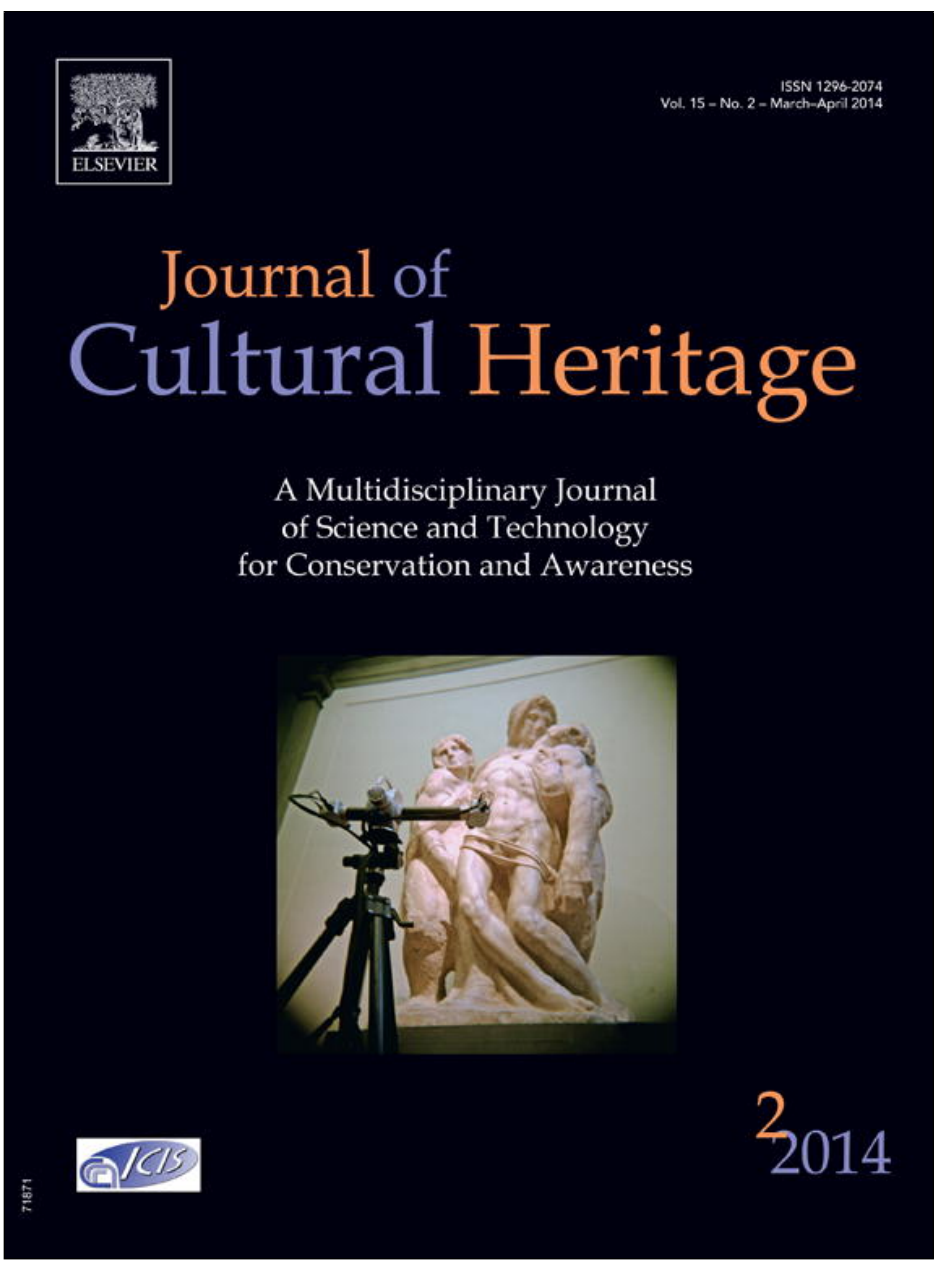

This article appeared in a journal published by Elsevier. The attached copy is furnished to the author for internal non-commercial research and education use, including for instruction at the authors institution and sharing with colleagues.

Other uses, including reproduction and distribution, or selling or licensing copies, or posting to personal, institutional or third party websites are prohibited.

In most cases authors are permitted to post their version of the article (e.g. in Word or Tex form) to their personal website or institutional repository. Authors requiring further information regarding Elsevier's archiving and manuscript policies are encouraged to visit:

http://www.elsevier.com/authorsrights 
Case study

\title{
Innovation in lighting for enhancing the appreciation and preservation of archaeological heritage
}

\author{
Santina Di Salvo \\ Department of Architecture, University of Palermo, Palermo, Italy
}

\section{A R T I C L E I N F O}

\section{Article history:}

Received 4 October 2012

Accepted 6 March 2013

Available online 10 April 2013

\section{Keywords:}

Lighting

Communication

Archaeology

Appreciation

Perception

Preservation

\begin{abstract}
A B S T R A C T
The cultural content of ancient sites highlights the importance of light, which is an essential tool for the correct appreciation of the historical value and memory of cultural heritage. This should be a new way to highlight significance of fragments in compliance of the surrounding, which has not the same characteristics, to signal a visual path, creating itineraries that involve the context. Light plays a very important role in creating emotion, suggestion, evocation and supporting the visitor experience. Innovative technological solutions should be designed taking into account the kind of landscape and morphological characteristics of the site. This paper presents the study of a sample of Italian and international case studies, seen in their historical, archaeological and museological aspects. The emphasis is on what should be the most effective lighting system for the monumental sites, one respecting the ruins and the authenticity of the site, while at the same time bringing out their architectural, historical and symbolic significance.
\end{abstract}

(c) 2013 Elsevier Masson SAS. All rights reserved.

\section{Introduction and research aims}

Lighting should be the responsibility of those interested in dealing with the issue of enhancing the public experience during their visit to an archaeological site. Recently, archaeological sites have experienced a gradual opening and a better projection to the outside world, to the point where archaeological ruins are now defined as sites of memory [1]. This change involves two main groups: the people responsible for the preservation of cultural heritage and the visitors. This transformation as also been confirmed by the increasing number of visitors to archaeological sites. Evidently, there is a greater interest in disseminating the knowledge derived from cultural heritage and transmitting these values to a non-specialist audience.

The most important aspects of an efficient artificial lighting design include:

- recovery of the historical memory of the ruins;

- perception of the archaeological fragment;

- indication of the hierarchy of paths and creation of guidance and teaching routes;

- enhancement of the archaeological heritage, in compliance with the ruins and their context;

- providing a more accessible reading of archaeology;

- establishing areas for walking, contemplation and conversation.

E-mail address: santina.disalvo@unipa.it
Light is a challenging task for museum professionals since it can also cause damage to heritage materials if used in an uncontrolled way [2]. This study has been based on an interdisciplinary approach. An archaeological context includes the soil, the site type, the layer from which the artifacts came from as well as other elements in that layer. The location where a fragment of an artifact was found is of primary importance. A site, properly valued and conveyed to the public contains important information about the settlers, their eating habits, their beliefs, as well as how their societies were organized [3]. Human prehistory and history are linked to archaeological remnants. Only by studying all the components of an archaeological site, one can have a thorough understanding of prehistoric cultural groups. For example, the Lascaux Caves in southwest France constitute a very important case, which contains some of the best-known Upper Paleolithic art. The combined effects of high-powered lights and the presence of too many visitors caused great damage to the site including the partial loss of archeological information through the fading of colorants. A longterm preventive measure consisted of building a replica, which was opened in 1983 and is located only 200 meters away from the original caves [4].

An underground archaeological site only requires artificial lighting, which can be easily controlled. In terms of risk management trade-offs, we must make a decision that minimizes the loss of value due to poor visual access and the loss of value due to permanent damage. In terms of ethics and visual access, we must balance the rights of our own generation with those of future generations. In terms of practical reality, we must generalize across a multitude of such decisions because objects differ in both their 


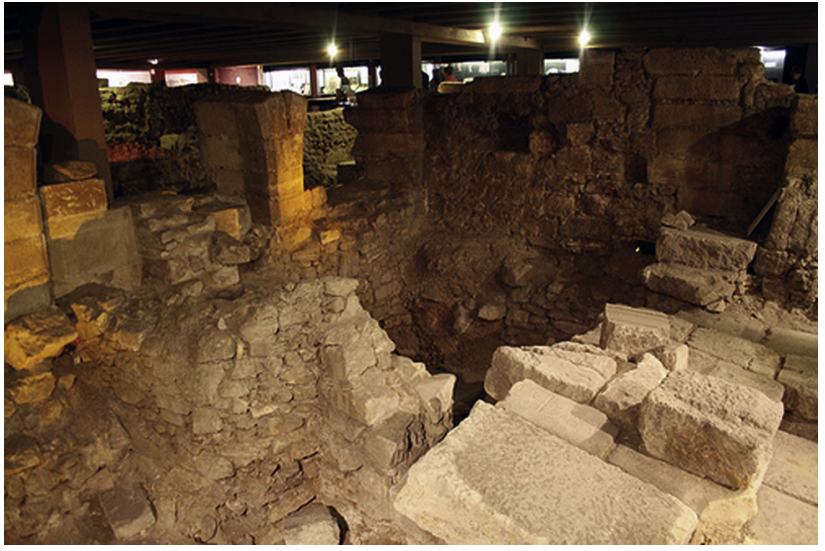

Fig. 1. Paris: archaeological crypt of Notre Dame.

sensitivity to light and their visibility. However, an outdoor archaeological site exposed to the sun and other environmental elements will probably suffer more damage when compared to an indoor site. Therefore, additional preventive measures must be taken into account for the outdoor site relative to its indoor counterpart since the former one has higher exposure to the elements. Colour temperature, colour rendering index, luminous intensity, luminous flux, illiminance/luminance, light exposure, quantity of ultraviolet radiation and luminous efficacy are the units, which inform us about the lighting characteristics [5]. Much of the variation in people's perception of whether light fading is a risk or not arises because this range of sensitivity is so dramatic - some colours in old objects that look fragile can indeed last many centuries, while some colours disappear within our own lifetime, or even in just a few years.

Monitoring campaigns carried out using light sensors or light dosimeters are helpful for determining if light exposure can be damaging to cultural heritage. The only way of determining if light exposure can be damaging is to conduct a light levels survey. These surveys are very common nowadays in museums and sites since these data provide a complete picture of the potential risks associated to lighting. In this work, a succession of cases studied is investigated in depth, to demonstrate the educational use of both natural and artificial light. The choice of sites presented is derived from the author's doctoral research, through own direct study and experience, specifically dedicated to indoor and outdoor archaeological sites, according to an experimental view of strategic projects that aim to recover the ancient built environment. In this paper, four examples were investigated in depth with the aim of demonstrating the educational use of lighting.

\section{Experimental}

\subsection{Light for communicating historical superimpositions and} functions: the archaeological crypt of Notre Dame

The archaeological crypt of Notre Dame is one of the largest underground museums in Europe, with 118 meters in length (Fig. 1). Gray stones indicate the presence of ruins under the square. Open to the public since 1980 , the crypt displays the foundations of structures built between Antiquity and the 19th century. Remains were discovered during the archeological excavations, which began in 1965 and it was also found that the surrounding structure ensured that these remains were protected [6].

This case represents an example of good lighting practice in which light is used to serve different purposes such as showing different historical periods and building remains as well as indicating the location of Roman baths and highlighting some architectural

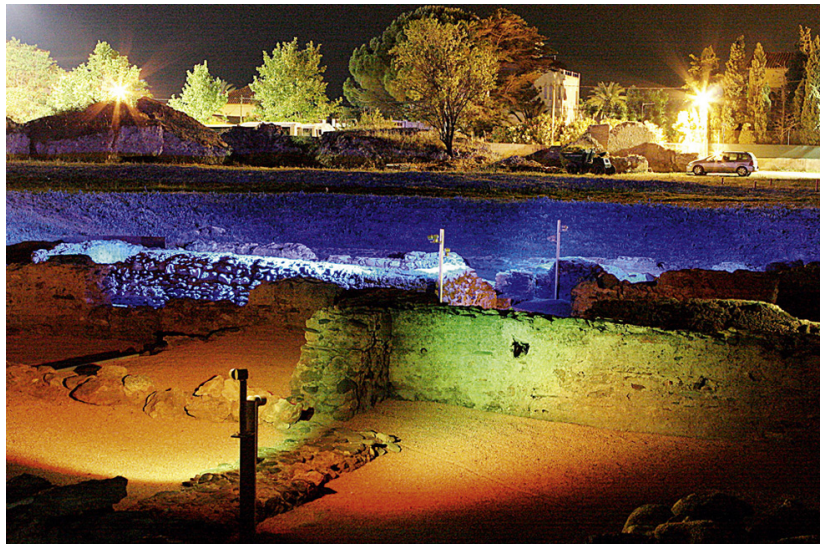

Fig. 2. Roses, Ciutadella: Roman and Greek Settlement ruins illuminated by LED equipment.

functions. The exhibition lighting was designed by Martini Light, famous Milan-based company that deals with architectural lighting, in 2005. The visit inside the crypt is like a real journey through time, where visitors explore the symbolic monuments of Lutetia. Three-dimensional models and direct light sources help showing the layers, the buildings, the decorations, the traditions and the functions. For example, red light is used for hypocausts in the calidarium while blue light is used for illuminating the frigidarium. The aim of the lighting design was that the elements of the exhibition were communicative and evocative. Halogen lamps were used with dichroic reflectors for reducing the heat load on the ancient stones. These illuminating devices offer the possibility of inserting colour filters and breakwater light lenses, which provide spectacular visual effects. Light can also be manipulated by visitors through the use of interactive consoles. In sum, the archaeological crypt of Notre Dame constitutes a good example of efficient lighting design adjusted to the need of the visitor and the preservation of the site.

\subsection{La Ciutadella de Roses}

La Ciutadella de Roses in Catalonia was protected like Conjunto Historico Artístico Nacional in 1961 and it is now a monument that forms part of the Cultural Heritage of National Interest (Fig. 2). The interventions in the Ciutadella include a series of activities for increasing the knowledge about its history, ensuring its preservation and providing a better enjoyment of the archaeological sites. Therefore, it was important to explore new methodological guidelines in terms of organization and strategy, considering the development of new scientific projects in accordance with the aims of the interventions of the archaeological site. The lighting design and installation of illumination systems was carried out by the company Aspecte (Banyoles, Catalonia), under the direction of engineer Martirià Figueras. She has investigated the complexity and diversity of La Ciutadella de Roses by launching an ambitious project that had the aim of providing visitors and residents with a comprehensive view of the site [7]. The museum opened in 2004 and since then it has established several didactic areas with the aim of presenting the history, revealing the different archaeological layers, and showing the ruins the ruins and artifacts belonging to ancient civilizations. Figueras encourages the interaction between visitors and the site, while minimizing the risks using reliable interventions. The creation of raised routes has made the passage of visitors to the archaeological area easier while limiting the direct access to the ruins and providing a way of preserving them. Walking inside the fortress is a continuous discovery process because it offers the possibility of enjoying magnificent views inside and outside the area limited by the fence. 
Figueras has explained how a luminous sign can highlight a single fragment in order to emphasize cultural importance. Artificial lighting must necessarily seek a constructive relationship with the ruins, while facilitating their reading with an innovative use of a modern material. The lighting design gives the opportunity to reveal the history of La Ciutadella de Roses following a route that focuses on six sections: the origins of the cultural site, the area of Greek settlements, the area of Roman occupation, the Monastery, the medieval town and the modern city. LED lighting fixtures, with a special shape, were installed at different strategic points with the aim of not disturbing visitors with unnecessary light contrasts and making the environments discernible. LED lamps give cold light, which is not harmful to the ruins and provide a way to help recognize the remains of settlements, to create various atmospheres through the use of different colours, and to help produce emotional impressions on the visitors. The use of LED lamps is an important new development for illumination of cultural heritage since the infrared radiation component is minimized and therefore they have important preservation implications. At the same time, LED lamps have a spectral power distribution that provide good colour rendering and better appreciation of details. For these reasons, LED lamps are highly recommended for the illumination of archaeological sites. Exhibition materials capable of capturing the attention of the visitor were used. These materials provided a non-destructive way of presenting the information about the settlement including time periods and various past functions or activities. This goal was achieved by following strategies that focused on the characteristics of different materials such as their different colours and other inherent elements of communication.

\subsection{Light used to create emotional responses and dramatic effects: London's Roman amphitheatre}

The roman amphitheatre of London was built in $70 \mathrm{AD}$. The display structure is about six meters under the square of the Guildhall Yard Art Gallery and the original wall is still visible along with the entrance from which gladiators, slaves and animals came into the arena. The presence of an advanced culture has archaeological, architectural and museographical implications. Therefore, the intervention strategy offered the possibility to conserve and properly show the original artifacts, including even a few of the original wooden fragments (Fig. 3). The intervention was conducted in 2004 by the London based firm Branson Coates Architecture. Their work concentrated on creating perspective effects, providing a remarkable charm for the visitor and recalling the dramatic and tragic atmosphere of gladiatorial games. The aim of the project was to study and reveal several aspects of Roman practices and traditions.

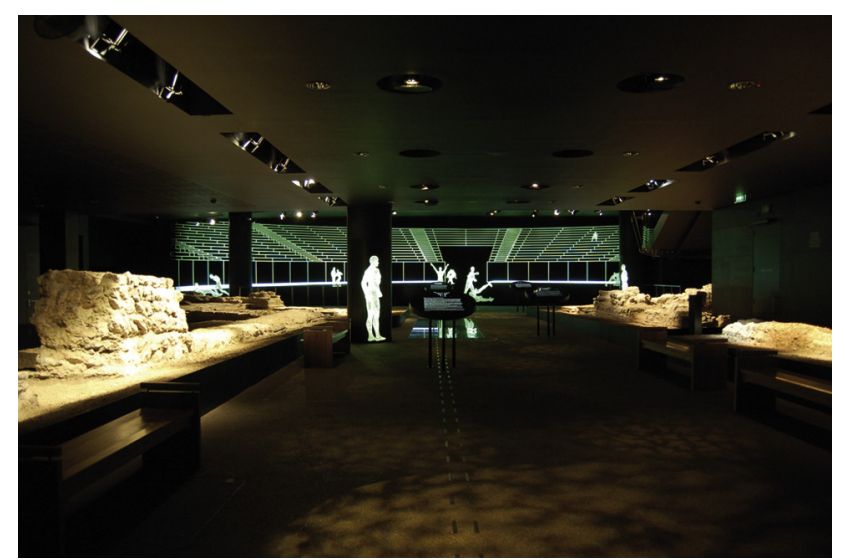

Fig. 3. London: lighting in London's Roman amphitheatre.

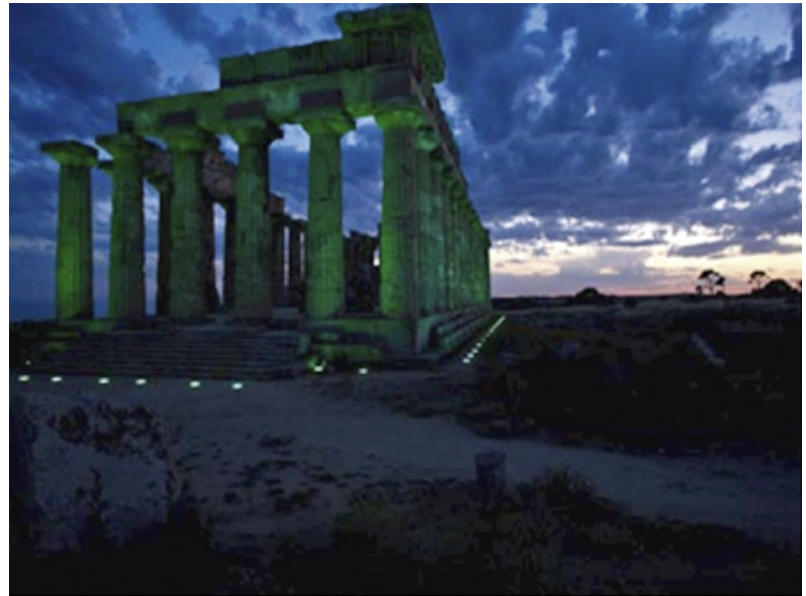

Fig. 4. Selinunte, Archaeological Park: Temple E.

This enabled a material and immaterial rebuilding of the environment, through the use of wireframe projections on the restored wall, with particular attention to the conservation and preservation of the original artifacts [8]. The shapes of gladiators, the stairs of the arena and the background of a cheering crowd recreate the magnitude of the amphitheatre. Lights and sounds do not distract the visitor, who is emotionally involved in the show. This intervention is an essential reference to show how projections can be employed as metaphors of an innovative restoration process involving the use of advanced technology.

\subsection{Light used to emphasize the landscape and for creating spectacular effects: Sicily, Selinunte}

The Archaeological Park of Selinunte was established in 1993, and today it is the largest and probably one of the most impressive in Europe. The ruins of the colossal Temples show that since its foundation Selinunte has been considered "the cradle of the Doric-style". This privileged destination for poets and travellers has always seemed like a large extension of the ruins. This is confirmed after inspecting photographs and reading Hackert's and Houel's report from the 18th century [9]. Temple E shown in Fig. 4 is the most popular attraction of the archaeological park. Since 2008, an experimental lighting intervention has been employed to highlight this monument. This project was commissioned by the Province of Trapani. The lighting design was characterized by the idea of conveying the magnificence of the original structure, trying to recall its former beauty. Flush mounting lamps were installed around the temple, while LED projectors evenly distribute the light to the entablature. The achieved effect is spectacular because there are changes in colour due to the use of dynamic light. The high levels of illumination achieved do not pose any risk to the structural integrity of the monument. The ultraviolet and infrared radiation components were removed resulting in reduced pollution and energy savings. Although this kind of intervention has benefits in terms of technological features, it could be wrong in terms of didactic or communicative purposes. The choice of colours does not have any conceptual connection with the archaeological site since it is only used for spectacular entertainment [10]. As a result, the spiritual and symbolic meaning of the Temple cannot be perceived. The final outcome is a real distraction from the monument itself and the landscape. Finally, the intervention leads to a misperception of the cultural content of the monument. In addition, we considered these aspects: 
- the drastic frontal lighting on each column reduced the contrasts necessary for the perception of fluting and others part of the monument like the interior;

- the uniform illumination on all fronts prevents the perception of the three-dimensionality of the Temple;

- the spectacular effects go beyond the idea of communicating the proper historical and symbolic value;

- in terms of visual impact, the installations are visible on the grounds during the day and in the evening. Dynamic light could have been used to highlight the three phases of construction of the Temple, but this goal has not been achieved.

\section{Conclusions}

This article demonstrates that archaeological contexts are an important opportunity to provide culture and education, but often educational function of interventions is poorly developed compared to expectations. It is undeniable that superimpositions of structures produced in different phases, the processes of destruction caused by time and by human activities, even the archaeological excavations and many other factors has led a quite difficult reading of the historic fabric, especially for non-specialists [11]. Cultural backgrounds influence people's perception of natural and artificial light and the tasks of the architects should be trying to make reliable interventions while seeking more useful strategies that help audiences experience and understand the site, for a wide range of public. This will result in better protection of our cultural heritage and more savings of public money, which is often wasted due to the implementation of incorrect interventions.

\section{References}

[1] G. Simmel, Die Ruine in Philosophische Kultur. Gesammelte Essays, Klinkhardt Leipzig, 1911, pp.121-7.

[2] R.L. Feller, Control of deteriorating effects of light on museum objects: heating effects of illumination by incandescent light, Museum News 46 (1968) 33-47.

[3] C. Balocco, R. Calzolari, Natural light design for an ancient building, J. Cult. Herit. 9 (2008) 172-178.

[4] M. Mauriac, Lascaux: the history of the discovery of an outstanding decorated cave, Adoranten, Scandinavian Society for Prehistoric Art, 2011, pp. 5-25.

[5] Commission Internationale de L'Éclairage. CIE 157: 2004 Control of damage to museum objects by optical radiation. Vienna, Austria (2004).

[6] M.C. Ruggieri Tricoli, Musei sulle Rovine. Architetture nel Contesto Archeologico, Lybra Immagine, Milan, 2007.

[7] A.M. Puig, A. Martin, La Colònia grega de Rhode (Roses, Alt Empordà), Museu d'Arqueologia de Catalunya, Girona, 2006.

[8] N. Bateman, B. Coates, The London amphitheatre excavations, "Britannia" 28 London, 1997, pp. 51-85.

[9] J.P. Hackert, F. Morel. Raccolta degli antichi monumenti esistenti fra Girgenti, Segeste e Selinunte: luoghi nella Sicilia. Franzetti a Torsanguigna (1810).

[10] A. Lauritano, E. Pulvirenti, L'illuminazione del Parco Archeologico di Selinunte, "Luce" n 6, Milan, 2005.

[11] G. Thomson, The museum environment, Butterworths, London, 1986. 